\title{
Perda auditiva induzida por ruído no exercício profissional do cirurgião-dentista: revisão da literatura
}

Noise-induced hearing loss in the professional exercise of the surgeon dentist: literature review

Pérdida de audición inducida por el ruido en el ejercicio profesional del cirujano-dentista: revisión de la literatura Amanda Rosa SILVEIRA

Tânia Adas SALIBA ${ }^{2}$

${ }^{I}$ Graduanda em Odontologia, Faculdade de Odontologia, UNESP Univ. Estadual Paulista, 16015-050 Araçatuba-SP, Brasil

${ }^{2}$ Professora Associada, Departamento de Odontologia Preventiva e Restauradora, Faculdade de Odontologia, UNESP Univ. Estadual Paulista, 16015 -050 Araçatuba - SP, Brasil Resumo

Perda auditiva induzida por ruído é uma lesão e patologia acumulativa, do tipo neurossensorial, irreversível e progressiva proveniente da exposição prolongada ao ruído no ambiente de trabalho. Altas intensidades de ruído provocam alterações psicológicas como ansiedade, estresse e alterações na pressão arterial, trazendo desconfortos e prejuízos físicos no convívio social. Os profissionais e acadêmicos da odontologia estão expostos a intensos níveis de ruídos, tornando este grupo suscetível à perda auditiva, resultantes da negligência de equipamentos de proteção individual. $\mathrm{O}$ objetivo deste trabalho foi realizar um levantamento bibliográfico do histórico dos ruídos, verificação dos níveis de ruídos, métodos preventivos da saúde ocupacional do cirurgião-dentista. A pesquisa foi realizada a partir de artigos que abordaram a ocorrência da perda auditiva induzida por ruído com enfoque na profissão odontológica, disponíveis nas bases de dados BVS, MEDLINE, PubMed e SciELO. É indiscutível a necessidade de controle do ruído em ambiente de trabalho, que é regulamentado por normas de segurança e medicina do trabalho. É importante a prevenção, por meio de medidas específicas como a utilização do protetor auricular, tornando o cirurgião-dentista menos vulnerável e proporcionando-lhe exercício profissional mais seguro.

Descritores: Odontologia; Perda Auditiva Provocada por Ruído; Qualidade de Vida; Ruído; Equipamento de Proteção Individual.

\section{Abstract}

Noise-induced hearing loss is an accumulative lesion and pathology, of the neurosensory type, irreversible and progressive resulting from prolonged exposure to noise in the workplace. High intensities of noise cause psychological changes such as anxiety, stress and changes in blood pressure, causing discomfort and physical damage in social life. Dentistry professionals and academics are exposed to intense noise levels, making this group susceptible to hearing loss, resulting from the neglect of personal protective equipment. The objective of this work was to carry out a bibliographic survey of the history of noise, verification of noise levels, preventive methods of occupational health of the dentist. The research was carried out from articles that addressed the occurrence of noise-induced hearing loss with a focus on the dental profession, available in the VHL, MEDLINE, PubMed and SciELO databases. There is an indisputable need to control noise in the workplace, which is regulated by occupational health and safety standards. Prevention is important, through specific measures such as the use of hearing protection, making the dentist less vulnerable and providing him with safer professional practice.

Descriptors: Dentistry; Hearing Loss, Noise-Induced; Quality of Life; Noise; Personal Protective Equipment.

\section{Resumen}

La pérdida auditiva inducida por ruido es una lesión y patología acumulativa, del tipo neurosensorial, irreversible y progresiva resultante de la exposición prolongada al ruido en el lugar de trabajo. Las intensidades de ruido altas causan cambios psicológicos como ansiedad, estrés y cambios en la presión arterial, causando molestias y daños físicos en la vida social. Los profesionales de la odontología y los académicos están expuestos a niveles intensos de ruido, lo que hace que este grupo sea susceptible a la pérdida de audición, como resultado de la negligencia del equipo de protección personal. El objetivo de este trabajo fue realizar un estudio bibliográfico de la historia del ruido, verificación de los niveles de ruido, métodos preventivos de salud laboral del dentista. La investigación se llevó a cabo a partir de artículos que abordaron la aparición de pérdida auditiva inducida por ruido con un enfoque en la profesión dental, disponible en las bases de datos VHL, MEDLINE, PubMed y SciELO. Existe una necesidad indiscutible de controlar el ruido en el lugar de trabajo, que está regulado por las normas de seguridad y salud laboral. La prevención es importante, a través de medidas específicas como el uso de protectores auditivos, lo que hace que el dentista sea menos vulnerable y le brinde una práctica profesional más segura.

Descriptores: Odontología; Pérdida Auditiva Provocada por Ruido; Calidad de Vida; Ruido; Equipo de Protección Personal.

\section{INTRODUÇÃO}

A definição de som é qualquer desarranjo vibratório em um meio elástico, que produza sensação auditiva. O ruído é um sinal acústico aperiódico, originado da superposição de vários movimentos de vibração com diferentes frequências que não apresentam relação entre si. O som é utilizado para descrever sensações prazerosas, enquanto o ruído sons irritantes e desagradáveis. Constitui a maior causa isolada de risco ocupacional em todo o mundo e dificilmente se verá um ambiente de trabalho totalmente desprovido desse risco ${ }^{1}$.

A Perda Auditiva Induzida por Ruído (PAIR) é provocada pela exposição por tempo prolongado ao ruído. Consideram-se como sinônimos: perda auditiva por exposição ao ruído no trabalho, surdez profissional, disacusia ocupacional, perda auditiva induzida por níveis de pressão sonora elevados, perda auditiva induzida por ruído ocupacional, perda auditiva neurossensorial por exposição continuada a níveis elevados de pressão sonora de origem ocupacional $^{2}$.
A exposição ocupacional ao ruído intenso lesiona as células ciliares do órgão de Corti, causando perda progressiva e irreversível da audição. Bilateral, simétrica e insidiosa, está diretamente relacionada ao tempo de exposição e susceptibilidade individual. Como manifestação auditiva, a exposição ocupacional ao ruído se associa ao zumbido, também chamado de acúfeno ou tínitus. Trata-se de um sintoma que produz extremo desconforto, de difícil tratamento, podendo, de acordo com sua gravidade, excluir do convívio social e até levar ao suicídio aqueles acometidos ${ }^{1,2}$.

Por apresentar um surgimento dos sintomas auditivos tardios $\mathrm{e}$ insidiosos, os profissionais geralmente só perceberão a dificuldade auditiva quando a lesão já está em estágio avançado. Os efeitos nocivos do ruído provoca exaustão física, alterações químicas, metabólicas e mecânicas do órgão sensorial auditivo, mas não se limitam apenas às lesões do aparelho auditivo, comprometem diversos outros órgãos, aparelhos e funções do 
organismo, entre os sintomas mais frequentes estão: dificuldade de compreensão de fala, zumbido, intolerância a sons intensos, cefaleia, tontura e irritabilidade. Podem apresentar manifestações sistêmicas, como elevação do nível geral de vigilância, aceleração da frequência cardíaca e respiratória, alteração da pressão arterial e da função intestinal, aumento do tônus muscular, aumento da produção de hormônios tireoidianos e estresse, contribuindo para o aumento do número de acidentes de trabalho; o que também leva à deterioração da qualidade de vida do trabalhador, acometendo em torno de $15 \%$ dos trabalhadores de países desenvolvidos segundo a Organização Mundial da Saúde $^{2}$. A PAIR acomete inicialmente as frequências agudas, os sons são percebidos de forma distorcida, e isso gera a incapacidade de conversar normalmente, podendo contribuir para o isolamento social, pela falta de comunicação com a família e amigos; a diminuição na capacidade de fiscalizar o ambiente de trabalho; ao alto risco de acidentes e bem-estar reduzido por causa do zumbido; as atividades cotidianas como ouvir televisão, músicas e telefone tornam-se difíceis ou impossíveis. As repercussões da PAIR podem se refletir a médio ou longo prazo, sendo necessário chamar a atenção para o real problema que afeta os trabalhadores de saúde bucal ${ }^{1}$.

No Brasil, o trabalho de prevenção das doenças ocupacionais e dos acidentes de trabalho teve início em 1943, com a Consolidação da Leis do trabalho (CLT) e desde então os cuidados com a audição do trabalhador que atua em ambientes ruidosos é intensificada. A Lei 6.514 de 22 de dezembro de 1977 da Consolidação de Leis do Trabalho, relaciona os parâmetros que proporcionam o conforto acústico dos trabalhadores juntamente com as normas da Associação Brasileira de Normas Técnicas (ABNT), sendo que a legislação do trabalho brasileira definiu que o limite máximo de ruído tolerável é de $85 \mathrm{~dB}$ NPS em uma jornada de trabalho de 8 horas; a NBR 10.152, indica que para consultório odontológico esse valor deve situar entre 35 e $45 \mathrm{~dB}^{2}$.

A notificação de acidentes e doenças relacionados ao ambiente de trabalho é importante para nortear políticas e programas voltados à saúde dos trabalhadores. Considera-se que a Saúde do Trabalhador é competência do Sistema Único de Saúde (SUS), desde a Constituição de 1989. O SUS foi fundamental no processo de reestruturação da rede de serviços públicos para adequar, qualificar e atender à demanda de doenças e acidentes relacionados ao trabalho, além de dar assistência ao trabalhador, com a finalidade de proporcionar melhorias na qualidade de vida no trabalho, relações pessoais e sociais ${ }^{3}$.

Como um componente da vigilância em saúde e visando à integralidade do cuidado, a
Vigilância em Saúde do Trabalhador (VISAT), coordenada pela Atenção Primária à Saúde (APS). Constituindo-se como um modelo de atenção integrado, é considerado processo saúde-doença do trabalho, no âmbito da promoção, da assistência e da vigilância. Essa integração da saúde do trabalhador na APS é ainda incipiente e descontinuada, uma vez que profissionais e serviços de atenção básica não estão preparados para estabelecer a relação entre o agravo e o trabalho e adotar os procedimentos adequados nessas situações. Tal situação torna os dados sobre a saúde dos trabalhadores na APS ainda escassos, e essa situação é ainda pior em relação à PAIR $^{3}$.

Em virtude disso, os cirurgiões-dentistas devem ser conscientizados sobre a existência da PAIR e das consequências danosas que representam para a saúde. A prevenção desses efeitos deve começar precocemente, durante a graduação, período de formação profissional para que, consciente dos riscos a que está exposto, possa evitar, ao invés de tratar os problemas decorrentes deles ${ }^{2,4}$. Este estudo teve como objetivo realizar um levantamento bibliográfico do histórico dos ruídos, verificação dos níveis de ruídos, métodos preventivos da saúde ocupacional do cirurgião-dentista, explicitar a legislação reguladora.

\section{MATERIAL E MÉTODO}

Esta revisão da literatura foi realizada em artigos com enfoque nos danos auditivos e não auditivos advindos da ocorrência da perda auditiva induzida por ruído, especialmente em profissionais e acadêmicos da odontologia.

Foram levantados trabalhos publicados entre 2002 e 2019, que abordaram a ocorrência da PAIR em trabalhadores expostos ao ruído, com enfoque na profissão odontológica, disponíveis nas bases de dados BVS, MEDLINE, PubMed e SciELO, com os descritores em português: "odontologia", "perda auditiva provocada por ruído", "qualidade de vida", "ruído", "equipamento de proteção individual" e os descritores em inglês: "dentistry", " hearing loss noise-induced", "quality of life"; "noise", "personal protective equipment". Foram selecionados 74 artigos, e destes excluídos 50 artigos que tinham enfoque principal em outras profissões, que não se referiam à perda auditiva induzida por ruído ocupacional em odontologia.

\section{RESULTADOS E DISCUSSÃO}

Os resultados foram organizados no Quadro 1, que apresenta os principais estudos encontrados.

\section{- Anatomia do ouvido e audição}

A orelha é um órgão sensorial especializado em duas funções: audição e equilíbrio. Ela é dividida em externa, média e interna, com os elementos neurais alojados nas estruturas da orelha interna. A orelha externa é constituída da orelha e do meato 
acústico externo. A orelha interna possui duas estruturas sensoriais principais. $\mathrm{O}$ aparelho vestibular, com seus canais semicirculares, é o transdutor sensorial para o sentido de equilíbrio.

\begin{tabular}{|c|c|c|}
\hline TÍ́TULO & AUTOR/ANO & CONCLUSÕES \\
\hline $\begin{array}{lr}\text { Adaptação } \\
\text { transcultural de um } \\
\text { instrumento de } \\
\text { avaliação do do } \\
\text { handicap auditivo } \\
\text { para portadores de } \\
\text { perda auditiva } \\
\text { induzida pelo ruído } \\
\text { ocupacional. }\end{array}$ & $\begin{array}{l}\text { Holanda et } \\
\text { al. }{ }^{1} \\
2011\end{array}$ & $\begin{array}{l}\text { A Escala de Inabilidades e Handicap Auditivo obteve } \\
\text { medidas psicométricas consideradas, em geral, } \\
\text { aceitáveis, considerando o tamanho reduzido da } \\
\text { amostra e o fato de os participantes não possuírem } \\
\text { perdas auditivas muito acentuadas. Portanto, tal escala } \\
\text { precisa ser testada em amostras maiores e e } \\
\text { representativas de trabalhadores brasileiros portadores } \\
\text { de PAIR, a fim de ser ratificada a sua utilidade para a } \\
\text { avaliação do handicap auditivo nessa população. }\end{array}$ \\
\hline $\begin{array}{lr}\text { Percepção do ruído } \\
\text { ocupacional e perda } \\
\text { auditiva } & \text { em } \\
\text { estudantes } & \text { de } \\
\text { Odontologia. } & \\
\end{array}$ & $\begin{array}{l}\text { Silva et al. }{ }^{17} \\
2016\end{array}$ & $\begin{array}{l}\text { Os estudantes de Odontologia da instituição } \\
\text { pesquisada conhecem os riscos da exposição ao ruído } \\
\text { ocupacional e sua relação com a perda auditiva. Os } \\
\text { participantes têm ciência das medidas de prevenção, } \\
\text { porém, não as utilizam. Não houve diferença estatística } \\
\text { quanto ao sexo e período em curso em relação à a } \\
\text { percepção dos riscos auditivos e medidas de prevenção. }\end{array}$ \\
\hline $\begin{array}{l}\text { Quality of life, } \\
\text { perception and } \\
\text { knowledge } \\
\text { dentists on noise }\end{array}$ & $\begin{array}{l}\text { Schettini e } \\
\text { Gonçalves }^{22} \\
2017\end{array}$ & $\begin{array}{l}\text { O ruído foi considerado, independente do gênero, } \\
\text { como nocivo à saúde e se relacionou com a percepção } \\
\text { de dor musculoesquelética. Foram relatados sintomas } \\
\text { e queixas associados ao ruído que podem impactar } \\
\text { negativamente a a atividade profissional dos } \\
\text { odontólogos, mas a maioria não adota medidas } \\
\text { preventivas. }\end{array}$ \\
\hline $\begin{array}{l}\text { O ambiente físico de } \\
\text { trabalho } \\
\text { odontológico: } \\
\text { iluminação, ruído e } \\
\text { conforto térmico. }\end{array}$ & $\begin{array}{l}\text { Ferreira et } \\
\text { al. } 23 \\
2006\end{array}$ & $\begin{array}{l}\text { É indiscutível que a saúde física e o bem estar psíquico } \\
\text { do profissional é tão importante quanto a sua } \\
\text { preocupação na melhoria técnica e científica, portanto, } \\
\text { realizar esforços no sentido de transformar o } \\
\text { consultório odontológico, em um local confortável e } \\
\text { ergonômico, é obrigação intransferível do profissional. }\end{array}$ \\
\hline $\begin{array}{lr}\text { Avaliação } & \text { do } \\
\text { desconforto } & \\
\text { ocupacional: } & \text { nível } \\
\text { de ruído de } & \text { uma } \\
\text { clínica } & \text { de } \\
\text { graduação. } & \end{array}$ & $\begin{array}{l}\text { Garbin } \quad \text { et } \\
\text { al. } .^{30} \\
2006\end{array}$ & $\begin{array}{l}\text { O profissional deve adotar medidas de comportamento } \\
\text { preventivo, como o uso do protetor auricular, mesmo } \\
\text { que não obrigatório, para evitar lesões auditivas a } \\
\text { longo de sua carreira. Cabe ressaltar que as } \\
\text { Universidades devem realizar avaliaçôes de } \\
\text { insalubridade nas clínicas de graduação, e assim } \\
\text { alertar os futuros profissionais dos riscos ocupacionais, } \\
\text { o qual estão expostos. }\end{array}$ \\
\hline
\end{tabular}

Quadro 1. Principais artigos incluídos na revisão de literatura

A cóclea da orelha interna possui os receptores sensoriais da audição, as células capilares são as estruturas que transmitem as vibrações do som para o sistema nervoso, ${ }^{5,6}$. O som agradável ou desagradável é a interpretação do cérebro da frequência, amplitude e duração das ondas sonoras. A frequência sonora é medida em ondas por segundo, ou hertz $(\mathrm{Hz})$. A orelha humana pode ouvir sons em uma média de frequência de $20 \mathrm{a} 20.000 \mathrm{~Hz}$, sendo a audição mais acurada entre 1.000 a $3.000 \mathrm{~Hz}^{5,7}$.

PAIR é a mudança permanente do limiar decorrente de um trauma acústico crônico e se caracteriza por ser do tipo sensório-neural, geralmente bilateral e simétrica, irreversível, de grau leve nas frequências baixas e severo nas frequências altas, com configuração audiométrica típica na faixa de frequências de 6000, 4000 e/ou $3000 \mathrm{~Hz}$, que progride lentamente nas frequências de 8000,2000 , 1000,500 e $250 \mathrm{~Hz}$ e atinge seu nível máximo, nas frequências mais altas, nos primeiros 10 a 15 anos de exposição estável a nível de pressão sonora (NPS) elevados e que interrompe sua progressão uma vez cessada a exposição sendo um comprometimento auditivo totalmente passível de prevenção ${ }^{1,8-10}$.

Existem três formas de perda auditiva: a condutiva (temporária), a central e a sensório-neural (permanente). Na perda auditiva condutiva, o som não pode ser transmitido a partir da orelha externa ou da orelha média. As causas da perda auditiva condutiva variam desde uma obstrução do canal auditivo com cera (cerume), ou líquido na orelha média devido a uma infecção, a doenças ou traumas que impedem a vibração do martelo, da bigorna ou do estribo. A perda auditiva central resulta de dano nas vias neurais entre a orelha e o córtex cerebral ou de danos no próprio córtex, como poderia ocorrer em um acidente vascular encefálico. A perda auditiva sensório-neural origina-se de lesões em estruturas da orelha interna, incluindo morte nas células do órgão de Corti, como resultado de exposição a sons altos ${ }^{5,11}$. - Normas regulamentadoras

A NR-06 trata dos Equipamentos de Proteção Individual (EPI) é todo produto ou dispositivo que tem por objetivo proteger $\mathrm{o}$ trabalhador, individualmente, contra riscos que ameacem sua segurança, saúde e integridade física durante a atividade laboral. O EPI deve oferecer proteção contra riscos oriundos de agentes ambientais existentes no local de trabalho (químicos, físicos e biológicos). Deve proteger também contra riscos de acidentes ou riscos de origem mecânica, por exemplo, queda de altura, choque elétrico, queda de objetos, entre outros. Para a proteção auditiva os EPIs utilizados estão no grupo $\mathrm{C}^{12}$.

A NR-07 trata do Programa de Controle Médico de Saúde Ocupacional e a partir da sua criação as empresas passaram a ser obrigadas a realizar exames médicos admissionais. Houve um importante avanço no âmbito da conservação auditiva, pois torna obrigatória a realização da audiometria tonal liminar. Todos os trabalhadores expostos a níveis excessivos de pressão sonora, independentemente do uso de protetor auditivo, devem ser submetidos a exames audiométricos de referência e sequenciais, utilizando-se um aparelho chamado audiômetro ${ }^{2,13}$.

A NR-09 trata do Programa de Prevenção de Riscos Ambientais (PPRA), cujo objetivo é a proteção da saúde e a integridade física dos trabalhadores, a partir de medidas de antecipação, reconhecimento, avaliação e controle dos riscos ambientais existentes ou que venham a existir no ambiente de trabalho. A proteção dos trabalhadores deve considerar também a proteção do meio ambiente e dos recursos naturais. Os riscos ambientais são os agentes físicos, químicos e biológicos existentes no ambiente de trabalho que, em função de sua natureza, concentração ou intensidade e tempo de exposição, são capazes de causar danos à saúde dos trabalhadores. Entre os agentes de riscos ocupacionais, existem os do tipo físico: vibração, radiação ionizante, pressão anormal, temperaturas externas, umidade e nível de ruído ${ }^{14}$.

O empregador deve manter um Programa de Prevenção de Risco Ambiental (PPRA), no qual os diversos riscos existentes no trabalho devem ser identificados e quantificados para direcionar as ações do Programa de Controle Médico de Saúde Ocupacional (PCMSO NR-7). Todo caso de perda auditiva induzida por ruído deve ser notificada 
compulsoriamente ao SUS, segundo a Portaria $\mathrm{n}^{\circ}$ 777 , de 28 de abril de 2004, e todo caso de perda auditiva induzida por ruído deve ser comunicado à Previdência Social, por meio de Comunicação de Acidentes de Trabalho 6 .

A NR-15 tem por objetivo determinar quais atividades deverão ser consideradas insalubres e indicar como essa caracterização deve ser feita: se por meio de avaliação qualitativa ou quantitativa. De acordo com a NR-15, entende-se por "Limite de Tolerância", a concentração ou intensidade máxima ou mínima, relacionada com a natureza e o tempo de exposição ao agente, que não causará danos à saúde do trabalhador, durante a sua vida laboral. No anexo 1 (Limites de tolerância para o ruído contínuo ou intermitente), estabelece em $85 \mathrm{~dB}$ o limite de ruído permitido para uma atividade de 8 horas diária, caso o trabalhador fique exposto a níveis de ruído acima de $115 \mathrm{~dB}$ ), sem proteção, a atividade é considerada insalubre. $\mathrm{O}$ anexo 2, estabelece $130 \mathrm{~dB}$ como limite de tolerância para ruído de impacto. Nos intervalos entre os picos, o ruído existente deverá ser avaliado como ruído contínuo ${ }^{4}$.

A NR-17, que trata da Ergonomia, tem como objetivo estabelecer parâmetros que permitam a adaptação das condições de trabalho às características psicofisiológicas dos trabalhadores, de modo a proporcionar um máximo de conforto, segurança e desempenho eficiente, estabelece que nos locais de trabalho onde são executadas atividades que exijam solicitação intelectual e atenção constante, o nível de ruído aceitável para efeito de conforto acústico é de $65 \mathrm{~dB}$. Não devemos confundir esse nível de conforto acústico $(65 \mathrm{~dB})$ com o nível de pressão sonora máximo admissível para jornada de oito horas previsto na NR15 (Atividades insalubres), que é de $85 \mathrm{~dB}$. O primeiro (NR17) se refere às condições de conforto acústico e o segundo (NR15) é medido para fins de caracterização da insalubridade ${ }^{15}$.

Para regular as condições de exposição das pessoas aos ruídos, a Associação Brasileira de Normas Técnicas (ABNT) criou a norma NBR 10.152 (ABNT, 1987) Acústica - avaliação do ruído ambiente em recintos de edificações visando o conforto dos usuários - procedimento, que estabelece limites para os ruídos de fundo nos ambientes construídos, objetivando o conforto acústico. No caso dos consultórios odontológicos, estabelece um limite de 35 a $45 \mathrm{~dB}$ na sala de atendimento, e de 40 a 50 $\mathrm{dB}$ na sala de espera, sendo o primeiro valor o de conforto, e o segundo o limite admissível para o ruído. Em relação às canetas de alta rotação, a NBR ISO 7785-1 da ABNT relata que a pressão sonora não deve ser superior a $80 \mathrm{~dB}$ e indica que esse valor deveria ser reduzido para $65 \mathrm{~dB}(\mathrm{ABNT}, 1999)^{11}$.

Estudo elaborado por Garbin et al. ${ }^{16}$, teve como objetivo realizar uma avaliação ocupacional do nível de ruído produzido em 40 equipos ocupados por
80 alunos divididos em dupla, durante atividade clínica, na disciplina de Clínica Integrada da Faculdade de Odontologia de Araçatuba UNESP. Os resultados mostraram que o nível de ruído, tanto a média, máxima e a mínima $(76,0 \mathrm{~dB} ; 83,4 \mathrm{~dB}$ e 70,0 $\mathrm{dB})$, respectivamente não consta de uma atividade insalubre conforme a NR-15 norma de segurança e medicina do trabalho e não estabelece a obrigatoriedade quanto ao uso do protetor auditivo. No entanto o valor máximo ficou acima do limitado de $80 \mathrm{~dB}$ da norma NR-17, e por fim todos os valores ficaram acima de $65 \mathrm{~dB}$ da norma NBR-10.152 de conforto acústico ${ }^{16}$.

Já o estudo realizado por Silva et al. ${ }^{17}$ com 63 estudantes de uma Instituição de Ensino Superior (IES) pública de Parnaíba, Piauí, teve taxa de resposta de 98,4\% (N=62). Os estudantes consideraram o ruído ocupacional nocivo à saúde $(82,3 \%)$ e o cirurgião-dentista um profissional susceptível à PAIR $(88,7 \%)$. Informações sobre a PAIR foram repassadas em algum momento a 53,2\% dos universitários, dos quais $81,8 \%$ relataram ter recebido na própria IES. Nenhum exame de audição foi realizado por $80,6 \%$. A pequena parcela que realizou o exame relatou que foi apenas por rotina $(66,7 \%)$ ou sensação de perda de audição $(33,3 \%)$. A legislação sobre a tolerância ao ruído (NR - 15) não é conhecida por $77,4 \%$ dos acadêmicos ${ }^{17}$.

\section{- PAIR na Odontologia}

A preocupação dos cirurgiões-dentistas com a perda auditiva induzida pelo ruído (PAIR) começou apenas na década de 50, quando surgiram os equipamentos de alta rotação movidos por turbinas que, por sua vez, são os equipamentos mais utilizados na prática clínica. Eles emitem um ruído intermitente e contínuo, o seu uso inadequado é o principal responsável pela prevalência de alterações auditivas ao longo da vida profissional ${ }^{18,19}$.

O cirurgião-dentista está sujeito a dois tipos de ruídos: o ruído ambiental, constituído pelos ruídos externos ao seu ambiente de trabalho, tais como o trânsito, vozes, compressor de ar (quando se localizar fora do ambiente), telefone, campainha, ruídos provenientes da sala de espera, choro e pelos ruídos provenientes de seu próprio ambiente de trabalho, tais como as canetas de alta e baixa rotação, sugador, compressor, cuspideira, peça reta, fotopolimerizador, autoclave, ar condicionado, compressor de ar (quando localizado no ambiente), sugadores de saliva, ultra-som, amalgamador, bombas de aspiração à vácuo e som ambiente ${ }^{18,20-23}$.

Em condições normais os níveis de ruído devem ficar entre 60 e 70 decibéis $(\mathrm{dB})$. Entre 70 e 90 dB, a sensação de desconforto aumenta e entre 90 e $140 \mathrm{~dB}$ há risco para a acuidade auditiva. De acordo com a legislação trabalhista brasileira, o limite máximo de ruído tolerável durante oito horas de trabalho é de $85 \mathrm{~dB}$. Os ruídos podem provocar 
dificuldades de concentração propiciando erros e reduzindo a produtividade em até $60 \%{ }^{20}$.

$\mathrm{O}$ estudo realizado por Schettini e Gonçalves $^{22}$ com 54 cirurgiões-dentistas da cidade de Curitiba - PR, observou-se que $55,5 \%$ dos profissionais consideraram o ruído de intensidade média, 79,6\% e disseram ser o ruído nocivo à saúde. Constatou-se que 59,2\% dos odontólogos conheciam alguma maneira de prevenir-se dos efeitos do ruído intenso. Entre essas maneiras de prevenção, foi referido $(51,8 \%)$ o uso de protetor auditivo. As maneiras diversas de controle do ruído $(14,8 \%)$ foram referidas, como: necessidade de lubrificação das peças de mão $(1,8 \%)$, diminuição do uso da caneta de alta rotação $(1,8 \%)$, localização de compressor e bomba a vácuo distantes do consultório $(1,8 \%)$, manutenção dos equipamentos $(1,8 \%)$, proteção acústica nos equipamentos $(3,7 \%)$ e equipamentos com menos barulho $(3,7 \%)^{22}$.

$\mathrm{O}$ estudo realizado por Albuquerque Neto et al. ${ }^{8}$ objetivou traçar o perfil audiométrico em 100 cirurgiões-dentistas na Cidade de Recife, com a finalidade de perceber a existência ou não de alterações auditivas, por meio de um estudo descritivo. Foram realizadas avaliação audiométrica (audiometria tonal, audiometria vocal SRT e IRF), impedânciometria e aplicação de questionário. Os resultados mostraram que $23 \%$ apresentaram perda auditiva sensorioneural bilateral, e a frequência auditiva mais afetada foi $3 \mathrm{KHz}$ na orelha direita e 6 $\mathrm{KHz}$ na orelha esquerda ${ }^{8}$.

O zumbido é um sintoma multifacetado e complexo que pode comprometer a qualidade de vida do indivíduo. No trabalhador exposto ao ruído, o zumbido tem sido associado à PAIR. As queixas mais frequentes referem-se à interferência no sono, persistência do zumbido, dificuldade para entender a fala, desânimo, frustração ou depressão, incômodo, irritação, inabilidade para relaxar e dificuldade de concentração ou confusão ${ }^{7,24}$.

Vulnerabilidade ao ruído no ambiente de trabalho é um conjunto de fatores que contribuem para aumentar ou diminuir o risco a que se está exposto, podem ser a duração e distribuição da exposição ao ruído, elevado nível da pressão sonora, desinformação por parte dos trabalhadores, negligência dos empregadores junto ao fornecimento de EPI e máquinas em inadequadas condições de funcionamento. Várias são as situações em que o trabalhador não percebe a evolução de sua doença relacionada ao trabalho, vindo a perder a eficiência no rendimento laboral, afastamentos temporários, chegando ao extremo de afastamentos por invalidez em pessoas relativamente jovens ${ }^{6,9}$.

- PAIR e efeitos extra-auditivos

Os efeitos nocivos do ruído não se limitam apenas às lesões do aparelho auditivo, mas comprometem diversos outros órgãos, aparelhos e funções do organismo, contribuindo dessa maneira para aumentar as preocupações e esforços na eliminação e controle desse agente. São efeitos auditivos reconhecidos: o zumbido, a mudança temporária e a mudança permanente do limiar auditivo (trauma acústico agudo e crônico) ${ }^{6,9,17,22,23}$.

Reações no sistema circulatório ocorrem sobre os vasos sanguíneos, com redução de seu diâmetro (vasoconstrição) e sobre o coração, com taquicardia, maior prevalência de hipertensão arterial sistêmica, bem como da frequência cardíaca e doenças cardiovasculares. O excesso de ruído eleva os níveis de estresse, o que aumenta a pressão arterial e a secreção de hormônios como adrenalina e cortisol ${ }^{9,22}$.

Há redução de secreção gástrica e salivar o que causa certa diminuição da velocidade de digestão. A exposição mais prolongada pode levar as alterações da função intestinal, a lesões teciduais dos rins e do fígado, queda de resistência a doenças infecciosas e disfunções na função reprodutora ${ }^{9,22}$. Há relatos de reflexos hiperativos, queixas de irritabilidade, fadiga e conflitos sociais entre os trabalhadores expostos ao ruído. A diminuição da sua capacidade de concentração, atenção, velocidade e precisão de movimentos; além da perda da inteligibilidade da fala com prejuízos para a comunicação entre profissional e paciente; trazendo irritabilidade e diminuição da produtividade no trabalho ${ }^{9,22}$.

Em estudo feito por Gambarra et al. ${ }^{25}$, foram entrevistados 48 cirurgiões-dentistas das Unidades de Saúde da Família do município de João Pessoa/PB. Foi observado que o tempo de atuação profissional mais predominante entre os entrevistados é de 11 a 30 anos, correspondendo a $74 \%$ do total. Os $62,50 \%$ dos cirurgiõesdentistas não considera o ruído prejudicial à sua audição, provavelmente não verificam a necessidade de utilizar o protetor auricular. Os sintomas otológicos relatados são: tontura $(27,05 \%)$, déficit de atenção $(12,5)$, alteração de sono $(16,7)$, alteração de humor $(18,75)$, cefaleia constante $(54,17)$, cansaço frequente $(41,7)$, distúrbios digestivos $(14,6)$ e zumbido $(35,41)^{25}$. Estudo feito por Gonçalves et al. ${ }^{26}$ com 219 cirurgiões-dentistas da cidade de Curitiba-PR, verificou que $66,25 \%$ dos indivíduos afirmaram conhecer maneiras para se proteger do ruído no trabalho, destes $87,03 \%$ citaram o uso de protetor auricular como uma das maneiras de se proteger do ruído ocupacional presente em seus consultórios, e $12,96 \%$ sugeriram a redução da exposição ao ruído com alterações no ambiente ou nos instrumentos de trabalho. Os resultados demonstraram uma dependência significativa entre a idade e o tempo de 
serviço (em anos) como odontólogo, ou seja, aqueles odontólogos com mais idade são os que possuem mais tempo de serviço com acúmulo de exposição ao ruído ocupacional, apresentando, assim, audição alterada. Os sintomas citados: perda auditiva $(64,55 \%)$, estresse $(10,12 \%)$, zumbido $(8,22 \%)$, irritabilidade $(7,59 \%)$, dor de cabeça $(5 \%)$, labirintite $(3,16 \%)$ e hipertensão $(1,26 \%)^{26}$.

$\mathrm{O}$ estudo realizado por Schettini e Gonçalves ${ }^{22}$ com 54 cirurgiões-dentistas da cidade de Curitiba - PR, as queixas e sintomas possivelmente relacionados à exposição ao ruído intenso foram a irritabilidade por $46,3 \%$, seguida pela dificuldade na compreensão da fala $(40,7 \%)$, sendo essas as queixas mais relatadas.

$\mathrm{Na}$ pesquisa de Silva et al. ${ }^{17}$ com 63 estudantes de uma Instituição de Ensino Superior (IES) pública de Parnaíba, Piauí, as queixas relatadas pelos alunos foram semelhantes às de alguns estudos com profissionais, dentre elas cefaleia constante, déficit de atenção, irritação, zumbido, intolerância a sons intensos, dificuldade de comunicação e estresse. Isso prova que, mesmo com menor exposição, os sintomas podem estar presentes antes mesmo da formação.

\section{- Prevenção do ruído}

Considerando que o ruído é um fator presente na vida do cirurgião-dentista desde a sua formação profissional e que a prevenção e o controle são os únicos meios para se preservar a sua saúde auditiva, recomenda-se que o cirurgião-dentista inclua $o$ protetor auricular no equipamento de proteção individual (EPI), uso de material fonoabsorvente para promover o isolamento acústico e realização de manutenção técnica periódica dos instrumentos rotatórios, a fim de minimizar o ruído no consultório odontológico objetivando minimizar a exposição ao ruído no consultório odontológico, bem como a ocorrência de lesões auditivas ${ }^{16,27}$.

Estudos demonstram que a utilização de protetores auditivos reduz de $20 \%$ a $78 \%$ os ruídos das canetas de alta rotação. Assim, o nível de ruído se torna suportável de acordo com as normas vigentes. Alguns autores relataram que a utilização de protetores auriculares pelo profissional poderá dificultar a comunicação com o paciente e a equipe de trabalho. Outra dificuldade apontada é que o protetor é de difícil limpeza e pode ser facilmente perdido $^{18}$.

Para evitar a incidência de sintomas auditivos e extra-auditivos em trabalhadores, se torna indispensável o reconhecimento e a avaliação de riscos ambientais para a audição, a adoção das medidas de proteção coletivas, de engenharia e administrativas, assim como a proteção individual acompanhada de ações de educação e motivação para o autocuidado e a preservação da saúde, além do monitoramento e gerenciamento audiométrico ${ }^{21,28}$.

\section{- Ambiente de trabalho e acidentes}

A avaliação da sensibilidade auditiva no exame admissional se mostrou insuficiente para identificar a real situação auditiva do trabalhador com espectro da neuropatia auditiva (ENA) e para propiciar encaminhamentos e orientação tanto ao trabalhador quanto ao empregador sobre as consequências dos efeitos do ruído nesses casos, o que compromete o reconhecimento de sinais de advertência, tornando a comunicação ineficiente e levando a um aumento no risco de ocorrência de acidente quando as características do posto de trabalho incluem ruído ${ }^{29}$.

O ruído no ambiente de trabalho ainda expõe o trabalhador a riscos para acidentes, como torções, ferimentos corto-contusos, fraturas que atingem membros superiores e inferiores além da coluna vertebral, fatores estes relacionados à falta de atenção e dispersão que o ruído laboral pode ocasionar ${ }^{6}$.

CONCLUSÃO

Verificou-se que as condições de trabalho dos cirurgiões-dentistas colaboram para o desenvolvimento da perda auditiva. Os profissionais têm consciência dos efeitos do ruído à audição, porém não tomam as medidas preventivas adequadas para evitar a possível perda auditiva, principalmente por meio do uso do EPI, por achar que não há risco, ou que está adaptado, o que na verdade revela sua saúde já debilitada e podem impactar negativamente o ambiente de trabalho.

Recomenda-se a implementação de programas de preservação auditiva, efetivos e coerentes com a realidade do profissional, manutenção periódica dos equipamentos de trabalho e à adequação do ambiente dentro dos padrões recomendados para melhor preservação da saúde. A notificação da PAIR constitui um instrumento valioso para vigilância da saúde do trabalhador. Estas informações se destinam à compreensão do quadro epidemiológico da PAIR, suas tendências e fatores que determinam o comportamento da doença. Sugerem-se estudos longitudinais que visem à vigilância epidemiológica nesta população.

\section{REFERÊNCIAS}

1. Holanda WTG, Lima MLC, Figueiroa JN. Adaptação transcultural de um instrumento de avaliação do handicap auditivo para portadores de perda auditiva induzida pelo ruído ocupacional. Cienc Saúde Coletiva. 2011;16(Suppl. 1):755-67.

2. Lopes AC, Melo ADP, Santos CC. Estudo dos limiares de audibilidade nas altas frequências em trabalhadores da área odontológica. Int Arch Otorhinolaryngol. 2012;16(2):226-31.

3. Pedroso HC, Gonçalves CGO. Primary care health professionals' perception and knowledge on notification of noise-induced hearing loss in Curitiba - Paraná. CoDAS. 2016;28(5):575-82. 
4. Ministério do Trabalho e Emprego (BR). Norma Regulamentadora $\mathrm{n}^{\circ} 15$, de 6 de julho de 1978. NR-15 Atividades e Operações Insalubres. Diário Oficial União. 1978 jul. 6 [acesso 2020 jan. 17]. Disponível em: http://www.trtsp.jus.br/geral/tribunal2/LEGIS/CL T/NRs/NR_15.html

5. Silverthorn DU. Fisiologia humana: uma abordagem integrada. 7th ed. Porto Alegre: ArtMed; 2017.

6. Lima da Silva JL, Dos Santos Costa F, Ferreira de Souza R, De Lyra Sousa J, De Souza Oliveira R. O ruído causando danos e estresse: possibilidade de atuação para a enfermagem do trabalho. Av Enferm. 2014;32(1):124-38.

7. Qsaibati ML, Ibrahim O. Noise levels of dental equipment used in dental college of Damascus University. Dent Res J. 2014;11(6):624-30.

8. Albuquerque Neto CL, Barbosa GM, Barboza Junior DS, Pires RMA, Ponzi EAC. Perdas auditivas induzidas pela prática da odontologia. $\mathbf{J}$ Bahiana. 2016; 5 [acesso 2020 jan. 17]. Disponível em: https://www5.bahiana.edu.br/index.php/odontolog ia/article/download/1397/855. Acesso em: 17 jan. 2020.

9. Ganime JF, Almeida da Silva L, Robazzi MLCC, Valenzuela SS, Faleiro SA. O ruído como um dos riscos ocupacionais: uma revisão de literatura. Enfermería Glob. 2010;(19):1-15.

10. Costa FOC, Pietrobon L, Fadel MAV, Regis Filho GI. Doenças de caráter ocupacional em cirurgiões-dentistas: uma revisão da literatura. In: Anais do XXVI ENEGEP; 2006 Out. 9-11; Fortaleza, CE.

11. Lacerda A, Melo SCS, Mezzadri SD, Zonta WG. Nível de pressão sonora de um consultório odontológico: uma análise ergonômica. Tuiuti Ciênc Cult. 2002;(26):17-24.

12. Ministério do Trabalho e Emprego (BR). Norma Regulamentadora $\mathrm{n}^{\circ}$ 6, de 8 de junho de 1978. NR6 Equipamento de Proteção Individual - EPI. Diário Oficial União. 1978 jul. 8 [acesso 2020 jan. 17]. Disponível em: http://www.trtsp.jus.br/geral/tribunal2/LEGIS/CL T/NRs/NR_6.html

13. Ministério do Trabalho e Emprego (BR). Norma Regulamentadora $\mathrm{n}^{\circ} 7$, de 8 de junho de 1978. NR7 Programa de Controle Médico de Saúde Ocupacional. Diário Oficial União 1978 jul. 8 [acesso: 2020 jan. 17]. Disponível em: http://www.trtsp.jus.br/geral/tribunal2/LEGIS/CL T/NRs/NR_7.html

14. Ministério do Trabalho e Emprego (BR). Norma Regulamentadora $\mathrm{n}^{\circ}$ 9, de 8 de junho de 1978. NR 9 Programa de Prevenção de Riscos Ambientais. Diário Oficial União 1978 jul. 8 [acesso 2020 jan. 17].

Disponível em:
http://www.trtsp.jus.br/geral/tribunal2/LEGIS/CL T/NRs/NR_9.html

15. Ministério do Trabalho e Emprego (BR). Norma Regulamentadora $\mathrm{n}^{\circ} 17$, de 8 de junho de 1978. NR 17 Ergonomia. Diário Oficial União 1978 jul. 8 [acesso 2020 jan. 17]. Disponível em: http://www.trtsp.jus.br/geral/tribunal2/LEGIS/CL T/NRs/NR_17.html

16. Garbin AJI, Saliba CAS, Ferreira NL, Ferreira NF. Evaluación de la incomodidad ocupacional: nivél del ruido de una clinica de graduación. Acta Odontol Venez. 2006;44(1):42-6.

17. Silva MS, Silva DP, Leal ES, Carvalho AGL, Miranda PAL, Falcão CAM. Percepção do ruído ocupacional e perda auditiva em estudantes de Odontologia. Rev ABENO. 2016;16(2):16-24.

18. Crosato E, Elizette L, Crosato EM, Biazevic MGH. Ruído no consultório odontológico: análise da pressão sonora em canetas de alta rotação. UFES Rev Odontol. 2007;9(2):4-7.

19. Fernandes JC, Santos LN, Carvalho HJM. Evaluation of acoustic performance of a dental office. Production. 2011;21(3):509-17.

20. Nogueira SA, Bastos LF, Costa ICC. Riscos ocupacionais em odontologia: revisão da literatura. J Health Sci. 2010;12(3):11-20.

21. Lourenço EA, Berto JMDR, Duarte SB, Greco JPM. Ruído em consultórios odontológicos pode produzir perda auditiva? Arqui Int Otorrinolaringol. 2011;15(1):84-8.

22. Schettini SRL, Gonçalves CGO. Quality of life, perception and knowledge of dentists on noise. Rev CEFAC. 2017;19(6):782-91.

23. Ferreira NF, Garbin AJI, Garbin CAS. O ambiente físico de trabalho odontológico: iluminação, ruído e conforto térmico. Odontol Soc. 2004;6(1):57-8.

24. Weber SR, Périco E. Zumbido no trabalhador exposto ao ruído. Rev Soc Bras Fonoaudiol. 2011;16(4):459-65.

25. Gambarra PAN, Valença AMG, Rocha AV, Cunha DGP. As repercussões do ruído ocupacional na audição dos cirurgiões-dentistas das unidades de saúde da família de João Pessoa /PB. Rev Bras Ciênc Saúde. 2012;16(3):361-70.

26. Gonçalves CGO, Lacerda ABM, Ribas A, Oliva FC, Almeida SB, Marques JM. Exposição ocupacional ao ruído em odontólogos do Paraná: percepções e efeitos auditivos. Rev Odontol UNESP. 2009;38(4):235-43.

27. Lopez TCV, LESSA LVL. Riscos físicos e ergonômicos de dentistas em clínicas de hospitais: um estudo de caso na cidade de Brasília - DF. In: Anais do XXX ENEGEP; 2010 Out. 12-15; São Carlos, SP.

28. Sonego MT, Santos Filha VAV, Moraes AB. Equipamento de proteção individual auricular: avaliação da efetividade em trabalhadores expostos a ruído. Rev CEFAC. 2016;18(3):667-76. 
29. Prestes MRD, Feitosa MAG, Sampaio ALL, Carvalho MFC, Meneses EA. O espectro da neuropatia auditiva pode contribuir para acidente de trabalho? O relato de uma investigação clínica. Rev Bras Saúde Ocup. 2012;37(125):181-8.

30. Garbin AJI, Garbin CAS, Ferreira NF, Ferreira NL. Avaliação do desconforto ocupacional II: nível de ruído de uma clínica de graduação. Acta odontol. Venez. 2006;44(1):42-6.

\section{CONFLITO DE INTERESSES}

Os autores declaram não haver conflitos de interesse.

AUTOR PARA CORRESPONDÊNCIA

\section{Amanda Rosa Silveira}

Rua Engenheiro Losck n ${ }^{\circ}$ 60, Centro, 19700-063 Paraguaçu

Paulista - SP, Brasil

amanda_silveir@hotmail.com

Submetido em 15/05/2020

Aceito em 02/07/2020 